\title{
THE OCCURRENCE OF ABNORMAL DARK ADAPTATION AND ITS RELATION TO VITAMIN A METABOLISM IN PATIENTS WITH CIRRHOSIS OF THE LIVER
}

\author{
BY ARTHUR J. PATEK, JR., AND CHARLES HAIG \\ (Research Service, First Division, Welfare Hospital, and the Department of Medicine, Columbia \\ University College of Physicians and Surgeons, New York City)
}

(Received for publication June 12, 1939)

Liver disease frequently is mentioned as a cause of vitamin A deficiency $(1,2)$. However, little evidence to support this opinion is present in the medical literature. Although many instances of coexisting liver disease and keratomalacia are reported, almost all of those recorded are associated with jaundice (3). In other reports no mention is made as to whether or not jaundice is present. Since the occurrence of jaundice without liver disease can lead to vitamin A deficiency, presumably through faulty absorption of the vitamin from lack of bile in the intestinal tract, such coincidence of keratomalacia and liver disease with jaundice may not be ascribed strictly to altered liver function. Moreover, as pointed out by Altschule (3), the diet of patients with liver disease often is restricted by aversion to food and by nausea, flatulence, and diarrhea. Intake of the vitamin may be insufficient in such cases. Recently Lasch (4) has reported that in 10 cases of diseases affecting the parenchyma of the liver, the vitamin A content of the blood was usually lower, whether icterus was present or not, than in 12 cases of non-hepatic diseases.

Pathological and experimental data concerning the relation between vitamin A deficiency and altered liver function have been inconclusive. Breusch and Scalabrino (5) found the content of vitamin $A$ to be reduced in livers of persons who died from cirrhosis. In similar analyses reported by Moore (6), the values for vitamin A in different diseased states varied too widely to permit ready interpretation. His data do not include analyses on cirrhotic livers. Kumagai (7) noted that regeneration of visual purple in the frog retina failed to occur after ligation of liver veins and after extirpation of the liver. Ralli (8) and her coworkers described the development of vitamin A deficiency in dogs with the "liver failure" that followed pancreatectomy. How- ever, in acute liver injury induced by chloroform or phosphorous poisoning there was no apparent failure of the rat to absorb and store the vitamin $(9,10)$. For the most part, experimental studies on this subject have been confined to the relation between vitamin $\mathrm{A}$ metabolism and bile flow $(11,12,13)$ rather than liver function.

It is pertinent, therefore, to determine whether vitamin A deficiency occurs in patients with liver disease whose intake of the vitamin is adequate and who are not jaundiced. The present paper, of which a preliminary account appeared previously (14) reports such studies on vitamin A metabolism in 24 patients with cirrhosis of the liver.

The patients ranged in age between 38 and 64 years. There were 17 males and 7 females. A history of alcoholism was obtained in 20 cases, and of syphilis in 8 , of whom 5 previously were treated with arsenicals. They manifested varied degrees of liver damage. Although 9 had been jaundiced previously, none was jaundiced at the time of testing. Nineteen had ascites on entry to the hospital. Most of the patients showed evidence of malnutrition. There were commonly weight loss and signs of vitamin deficiency, such as peripheral neuritis, glossitis, and pellagrous dermatitis. In a number of patients the injected conjunctivae and gray, lusterless sclerae suggested the specific lack of vitamin A. In several cases keratinized epithelium was obtained by corneal scrapings. In 3 cases keratinizing metaplasia of the pancreatic ducts was seen on pathological examination. None was aware of night blindness on direct questioning, although tests of 19 patients demonstrated night blindness.

\section{METHODS}

The nutrition of the patients with reference to vitamin A was estimated by means of an adaptometer for measuring dark adaptation. This procedure assumes a quantita- 
tive relation between available vitamin $A$ and the regeneration of visual purple in the retinal rods during dark adaptation. A number of recent studies $(15,16,17)$ have shown this relationship to exist. The particular instrument used (18) allows examination of the full course of dark adaptation after exposure to a preadapting light. The curves are precise and reproducible, the physiological day-to-day variation being greater than the experimental error. The procedure is controlled with regard to brightness, duration, color and retinal location of the preadapting light as well as the ensuing dark adaptation of a sharply defined retinal area. The white preadapting brightness of 4700 millilamberts ${ }^{1}$ is viewed by the subject for 4 minutes. The test light, a flash of 0.2 second's duration, passes through a violet filter (Corning 511) which transmits the spectrum only below $460 \mathrm{mu}$. The retinal region tested is a circular area whose diameter subtends $3^{\circ}$ visual angle and is located $7^{\circ}$ nasally in the right eye. No artificial pupil was used, as it has been demonstrated that the pupillary reflex error in rod measurements is clinically negligible under the conditions of the present experiments (19).

${ }^{1}$ Millilamberts $=$ foot candles $\times 1.0764$; micromicrolamberts $=$ millilamberts $\times 10^{\circ}$.

\section{Types of dark adaptation}

In Figure 1 is illustrated the course of dark adaptation of 15 normal subjects (shaded area 1) by a plot of log threshold brightness in micromicrolamberts ${ }^{1}$ as a function of time in the dark. After a 4-minute exposure to white light 4700 millilamberts, the first phase $(a)$ of cone adaptation takes place, to be followed by the rod phase (b). If the normal person is subjected to a diet low in vitamin $\mathrm{A}$ for a sufficient length of time, the final threshold becomes raised not only for the rods but also for the cones $(20,21,22)$. The cone changes were noted originally in cases of liver cirrhosis (14). A similar curve of " simple deficiency" is seen in the patient with obstructive jaundice (Figure 1, Curve 2), whose night blindness is related to malabsorption of vitamin A. However, in patients with cirrhosis of the liver, there may be not only a raised final threshold indicative of vitamin A deficiency, but a time

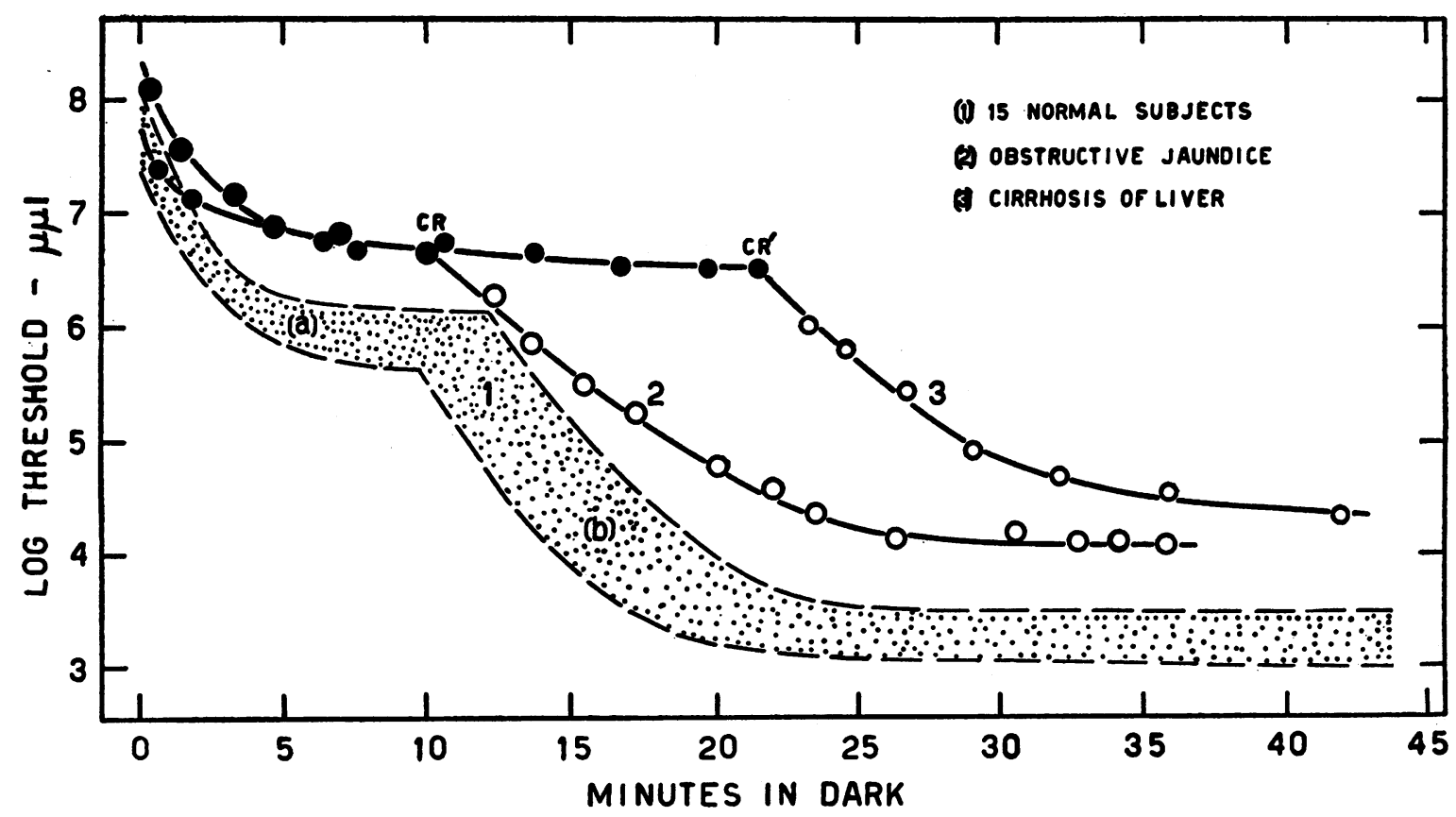

Fig. 1. Normal and Abnormal Dark Adaptation Curves

The log threshold brightness is expressed in micromicrolamberts (millilamberts $\times 10^{9}$ ). The points indicate single observations. Those which appear violet to the subject fall on the cone portion of the curve and are denoted by solid symbols. Those which appear colorless to the subject fall on the rod portion of the curve and are denoted by open symbols.

The shaded area (1) represents the range of variation in 15 normal subjects as well as the extent of extreme daily variation. Curve 2 is that of a patient with obstructive jaundice. This corresponds in shape to the curve of "simple" vitamin A deficiency. In Curve 3, from a patient with cirrhosis of the liver, the rod-cone transition point is displaced and the final thresholds for both cones and rods are elevated. 
factor as well, in which the rod phase is delayed (Figure 1, Curve 3). This is illustrated in Figure 1 by the difference between cone-rod transition points $C R$ and $C^{1}$ (Curves 2 and 3 ). In certain instances this time factor, or speed, alone is altered and the final threshold is normal. In others, both the speed and final threshold are abnormal. On this account it is essential to the use of dark adaptation in clinical studies that a procedure be employed which follows the entire course of adaptation rather than one which confines itself to a single determination of the final rod threshold.

\section{Measurements}

For the purpose of this study 3 points in the curve are considered to be of especial importance, namely the cone-rod transition point, the 20 -minute reading and the 40 -minute reading. The transition point gives an indication of the speed of adaptation; the 20 -minute reading is the resultant of several factors including speed, slope (which is a function of speed) and threshold. If any change in either speed or threshold occurs it is generally discernible at the 20 -minute reading. The 40-minute reading is the final value reached with complete dark adaptation. Since normal values fall within a narrow, defined range, an appreciable shift at any of these 3 points is considered to be abnormal.

Control observations on 15 normal subjects are recorded in Table $I$. The cone-rod transition point always occurred before 13 minutes; the 20 minute value did not exceed a $\log I$ value of 4.0 ; the final threshold did not exceed a $\log I$ value of 3.5. Differences of $0.3 \mathrm{log}$ units are considered significant in the same subject. Such changes correspond to 100 per cent alterations in brightness.

In Table II are recorded observations on $35 \mathrm{pa}-$ tients with various diseases, including rheumatoid arthritis, lobar pneumonia, chronic nephritis, diabetes mellitus, essential hypertension, renal stone, multiple sclerosis. In general, the values agreed with those obtained from normal subjects. Minimal changes occurred in certain of these patients. However, significant changes occurred in several with renal stone. Although less constant, these findings confirm in part the observations of Ezickson and Feldman (23). Of 12 cases of renal
TABLE 1

Dark adaptation data on 15 normal subjects

\begin{tabular}{|c|c|c|c|c|c|c|}
\hline \multirow{2}{*}{ Case } & \multirow{2}{*}{ Age } & \multirow{2}{*}{ Sex } & \multicolumn{3}{|c|}{$\begin{array}{l}\text { Log threshold } \\
\text { (micromicrolamberts) }\end{array}$} & \multirow{2}{*}{$\begin{array}{l}\text { Cone-rod } \\
\text { transi- } \\
\text { tion } \\
\text { point }\end{array}$} \\
\hline & & & $\stackrel{8}{\text { minutes }}$ & $\begin{array}{c}20 \\
\text { minutes }\end{array}$ & $\begin{array}{c}40 \\
\text { minutes }\end{array}$ & \\
\hline $\begin{array}{l}\text { R. M. } \\
\text { W. M. } \\
\text { L. L. } \\
\text { C. H. } \\
\text { F. K. } \\
\text { W. G. } \\
\text { D. B. } \\
\text { J. P. } \\
\text { D. R. } \\
\text { E. H. } \\
\text { A. P. } \\
\text { M. A. } \\
\text { J. P. } \\
\text { D. S. } \\
\text { R. D. }\end{array}$ & $\begin{array}{l}\text { years } \\
30 \\
30 \\
30 \\
40 \\
40 \\
40 \\
34 \\
27 \\
26 \\
40 \\
34 \\
25 \\
26 \\
40 \\
30\end{array}$ & $\begin{array}{l}\mathbf{M} \\
\mathbf{M} \\
\mathbf{F} \\
\mathbf{M} \\
\mathbf{M} \\
\mathbf{M} \\
\mathbf{F} \\
\mathbf{M} \\
\mathbf{F} \\
\mathbf{F} \\
\mathbf{M} \\
\mathbf{F} \\
\mathbf{M} \\
\mathbf{M} \\
\mathbf{M}\end{array}$ & $\begin{array}{l}5.8 \\
5.6 \\
6.0 \\
6.2 \\
6.0 \\
6.2 \\
6.1 \\
6.0 \\
6.1 \\
6.1 \\
5.7 \\
6.0 \\
5.9 \\
6.1 \\
5.8\end{array}$ & $\begin{array}{l}3.7 \\
3.5 \\
3.8 \\
3.9 \\
3.6 \\
3.7 \\
3.9 \\
3.6 \\
4.0 \\
3.8 \\
3.5 \\
3.8 \\
3.7 \\
4.0 \\
3.5\end{array}$ & $\begin{array}{l}3.2 \\
3.4 \\
3.2 \\
3.4 \\
3.2 \\
3.5 \\
3.3 \\
3.3 \\
3.3 \\
3.4 \\
3.3 \\
3.0 \\
3.3 \\
3.5 \\
3.0\end{array}$ & $\begin{array}{c}\text { minutes } \\
12.1 \\
10.6 \\
11.8 \\
12.0 \\
10.0 \\
10.3 \\
12.0 \\
10.6 \\
10.6 \\
12.0 \\
10.4 \\
12.0 \\
9.6 \\
12.0 \\
10.8\end{array}$ \\
\hline
\end{tabular}

TABLE II

Dark adaptation data on patients with various diseases

\begin{tabular}{|c|c|c|c|c|c|c|c|}
\hline \multirow{2}{*}{ Case } & \multirow{2}{*}{ Age } & \multirow{2}{*}{ Sex } & \multicolumn{3}{|c|}{$\begin{array}{c}\text { Log } \\
\text { threshold } \\
\text { (micromicro- } \\
\text { lamberts) }\end{array}$} & \multirow{2}{*}{$\begin{array}{c}\text { Cone- } \\
\text { rod } \\
\text { transi- } \\
\text { tion } \\
\text { point }\end{array}$} & \multirow{2}{*}{ Diagnoses } \\
\hline & & & $\begin{array}{c}8 \\
\text { min- } \\
\text { utes }\end{array}$ & $\begin{array}{c}20 \\
\text { min- } \\
\text { utes }\end{array}$ & $\begin{array}{c}40 \\
\text { min- } \\
\text { utes }\end{array}$ & & \\
\hline $\begin{array}{l}\text { M. L. } \\
\text { H. M. } \\
\text { E. M. } \\
\text { H. T. } \\
\text { M. H. } \\
\text { S. G. } \\
\text { A. J. } \\
\text { M. L. } \\
\text { S. L. } \\
\text { A. C. } \\
\text { A. L. } \\
\text { J. S. } \\
\text { G. O. } \\
\text { R. R. } \\
\text { E. R. } \\
\text { T. R. } \\
\text { M. M. } \\
\text { M. G. } \\
\text { J. S. } \\
\text { R. D. } \\
\text { J. C. } \\
\text { R. N. } \\
\text { R. B. } \\
\text { A. R. } \\
\text { J. T. } \\
\text { B. H. } \\
\text { F. F. } \\
\text { R. S. } \\
\text { D. P. } \\
\text { J. F. } \\
\text { L. C. } \\
\text { B. A } \\
\text { P. T. } \\
\text { P. E. } \\
\text { W. W. }\end{array}$ & $\begin{array}{c}\text { years } \\
26 \\
46 \\
58 \\
31 \\
42 \\
54 \\
28 \\
63 \\
31 \\
54 \\
50 \\
28 \\
53 \\
46 \\
57 \\
72 \\
34 \\
35 \\
24 \\
20 \\
65 \\
38 \\
48 \\
36 \\
23 \\
39 \\
58 \\
39 \\
25 \\
28 \\
25 \\
30 \\
30 \\
40 \\
35\end{array}$ & $\begin{array}{l}\mathbf{F} \\
\mathbf{F} \\
\mathbf{F} \\
\mathbf{M} \\
\mathbf{F} \\
\mathbf{F} \\
\mathbf{F} \\
\mathbf{F} \\
\mathbf{M} \\
\mathbf{F} \\
\mathbf{M} \\
\mathbf{M} \\
\mathbf{M} \\
\mathbf{M} \\
\mathbf{F} \\
\mathbf{M} \\
\mathbf{F} \\
\mathbf{M} \\
\mathbf{M} \\
\mathbf{F} \\
\mathbf{M} \\
\mathbf{F} \\
\mathbf{F} \\
\mathbf{M} \\
\mathbf{M} \\
\mathbf{M} \\
\mathbf{F} \\
\mathbf{F} \\
\mathbf{F} \\
\mathbf{M} \\
\mathbf{M} \\
\mathbf{M} \\
\mathbf{M} \\
\mathbf{M} \\
\mathbf{M}\end{array}$ & $\begin{array}{l}5.9 \\
5.8 \\
6.0 \\
5.9 \\
6.0 \\
6.1 \\
5.9 \\
6.5 \\
6.0 \\
6.3 \\
6.4 \\
6.0 \\
6.6 \\
6.2 \\
6.5 \\
6.6 \\
5.8 \\
5.8 \\
5.9 \\
5.6 \\
6.2 \\
6.0 \\
6.2 \\
6.2 \\
5.8 \\
5.6 \\
6.0 \\
6.2 \\
6.0 \\
6.2 \\
5.7 \\
6.0 \\
6.0 \\
6.7 \\
6.9\end{array}$ & $\begin{array}{l}3.9 \\
3.8 \\
3.7 \\
3.7 \\
4.0 \\
4.0 \\
3.4 \\
4.0 \\
3.8 \\
4.6 \\
4.0 \\
3.8 \\
4.1 \\
4.0 \\
5.9 \\
5.9 \\
3.8 \\
3.5 \\
3.5 \\
3.6 \\
4.1 \\
4.2 \\
3.6 \\
4.0 \\
3.3 \\
3.5 \\
4.0 \\
3.7 \\
4.0 \\
4.4 \\
3.7 \\
4.2 \\
3.8 \\
4.4 \\
4.0\end{array}$ & $\begin{array}{l}3.4 \\
3.0 \\
3.2 \\
3.4 \\
3.4 \\
3.2 \\
3.3 \\
3.6 \\
3.1 \\
3.5 \\
3.8 \\
3.7 \\
3.9 \\
3.1 \\
3.4 \\
3.9 \\
3.2 \\
3.3 \\
3.2 \\
3.2 \\
3.4 \\
3.4 \\
3.3 \\
3.3 \\
3.1 \\
2.9 \\
3.5 \\
3.2 \\
3.3 \\
3.5 \\
3.2 \\
3.4 \\
3.3 \\
4.0 \\
3.4\end{array}$ & $\begin{array}{c}\text { minutes } \\
13.0 \\
13.0 \\
11.0 \\
8.5 \\
13.7 \\
11.0 \\
9.5 \\
13.0 \\
11.0 \\
14.8 \\
9.4 \\
10.4 \\
10.8 \\
9.4 \\
19.0 \\
18.7 \\
11.3 \\
9.4 \\
10.0 \\
12.5 \\
12.8 \\
12.3 \\
11.5 \\
12.3 \\
9.5 \\
10.0 \\
9.0 \\
11.0 \\
13.2 \\
12.0 \\
11.5 \\
12.5 \\
11.2 \\
10.0 \\
10.6\end{array}$ & $\begin{array}{l}\text { Rheumatoid arthritis } \\
\text { Rheumatoid arthritis } \\
\text { Rheumatoid arthritis } \\
\text { Rheumatoid arthritis } \\
\text { Renal stone } \\
\text { Renal stone } \\
\text { Renal stone } \\
\text { Renal stone } \\
\text { Renal stone } \\
\text { Renal stone } \\
\text { Renal stone } \\
\text { Renal stone } \\
\text { Renal stone } \\
\text { Renal stone } \\
\text { Renal stone } \\
\text { Renal stone } \\
\text { Lobbar pneumonia } \\
\text { Lobar pneumonia } \\
\text { Lobar pneumonia } \\
\text { Lobar pneumonia } \\
\text { Bronchial asthma } \\
\text { Essential hypertension } \\
\text { Essential hypertension } \\
\text { Chronic nephritis } \\
\text { Chronic nephritis } \\
\text { Pellagra } \\
\text { Diabetes mellitus } \\
\text { Diabetes mellitus } \\
\text { Amyloid disease } \\
\text { Multiple sclerosis } \\
\text { Multiple sclerosis } \\
\text { Multiple sclerosis } \\
\text { Multiple sclerosis } \\
\text { Multiple sclerosis } \\
\text { Multiple sclerosis }\end{array}$ \\
\hline
\end{tabular}

stone, 4 showed slight elevation of final threshold, 1 showed slight delay of rod function, while 3 showed marked delay of rod function, quite like 
the alterations seen in patients with cirrhosis of the liver.

Although the age and sex distribution of the above 2 groups differs from that of our patients with cirrhosis of the liver, earlier studies have indicated these differences to be of little, if any, significance.

Observations on 24 cases of cirrhosis are recorded in Table III. Fifteen showed delay at the

TABLE III

Dark adaptation data on patients with cirrhosis of the liver

\begin{tabular}{|c|c|c|c|c|c|c|}
\hline \multirow{2}{*}{ Case } & \multirow{2}{*}{ Age } & \multirow{2}{*}{ Sex } & \multicolumn{3}{|c|}{$\begin{array}{l}\text { Log threshold } \\
\text { (micromicrolamberts) }\end{array}$} & \multirow{2}{*}{$\begin{array}{c}\text { Cone-rod } \\
\text { transi- } \\
\text { tion } \\
\text { point }\end{array}$} \\
\hline & & & $\stackrel{8}{\text { minutes }}$ & $\stackrel{20}{\text { minutes }}$ & $\begin{array}{c}40 \\
\text { minutes }\end{array}$ & \\
\hline $\begin{array}{l}\text { J. H. } \\
\text { W. C. } \\
\text { B. M. } \\
\text { B. M. } \\
\text { A. L. } \\
\text { R. C. } \\
\text { C. J. } \\
\text { R. T. } \\
\text { E. W. } \\
\text { V. T. } \\
\text { J. K. } \\
\text { M. F. } \\
\text { J. H. } \\
\text { J. L. } \\
\text { A. LeC. } \\
\text { M. M. } \\
\text { F. S. } \\
\text { E. G. } \\
\text { W. H. } \\
\text { R. B. } \\
\text { M. DeF. } \\
\text { E. A. } \\
\text { M. O. } \\
\text { P. K. }\end{array}$ & $\begin{array}{c}\text { years } \\
60 \\
63 \\
55 \\
40 \\
57 \\
46 \\
64 \\
52 \\
41 \\
49 \\
48 \\
45 \\
61 \\
60 \\
58 \\
49 \\
53 \\
45 \\
38 \\
60 \\
49 \\
45 \\
38 \\
45\end{array}$ & $\begin{array}{l}\mathbf{M} \\
\mathbf{M} \\
\mathbf{M} \\
\mathbf{M} \\
\mathbf{M} \\
\mathbf{M} \\
\mathbf{M} \\
\mathbf{M} \\
\mathbf{F} \\
\mathbf{M} \\
\mathbf{M} \\
\mathbf{F} \\
\mathbf{M} \\
\mathbf{M} \\
\mathbf{M} \\
\mathbf{F} \\
\mathbf{M} \\
\mathbf{F} \\
\mathbf{M} \\
\mathbf{M} \\
\mathbf{F} \\
\mathbf{F} \\
\mathbf{F} \\
\mathbf{M}\end{array}$ & $\begin{array}{l}6.3 \\
6.3 \\
6.2 \\
6.3 \\
6.2 \\
6.5 \\
7.1 \\
6.0 \\
6.2 \\
6.2 \\
6.3 \\
6.1 \\
6.5 \\
6.2 \\
6.5 \\
7.0 \\
6.3 \\
6.9 \\
7.0 \\
6.0 \\
6.4 \\
6.0 \\
6.2 \\
6.0\end{array}$ & $\begin{array}{l}6.3 \\
5.6 \\
6.0 \\
6.0 \\
5.9 \\
5.4 \\
6.9 \\
4.4 \\
4.6 \\
4.9 \\
5.0 \\
4.4 \\
4.8 \\
4.4 \\
5.2 \\
4.6 \\
4.4 \\
4.0 \\
3.9 \\
4.3 \\
4.0 \\
4.0 \\
5.9 \\
3.8\end{array}$ & $\begin{array}{l}3.3 \\
3.9 \\
4.0 \\
3.3 \\
3.3 \\
4.2 \\
5.0 \\
3.9 \\
3.4 \\
3.5 \\
4.3 \\
3.4 \\
4.0 \\
4.0 \\
4.3 \\
4.1 \\
4.0 \\
3.7 \\
3.7 \\
3.5 \\
3.4 \\
3.7 \\
3.4 \\
3.2\end{array}$ & $\begin{array}{c}\text { minutes } \\
21.5 \\
16.8 \\
19.5 \\
19.0 \\
18.0 \\
15.5 \\
19.0 \\
15.5 \\
15.3 \\
15.0 \\
15.5 \\
14.5 \\
13.3 \\
11.6 \\
11.8 \\
13.3 \\
13.0 \\
11.9 \\
10.3 \\
10.5 \\
12.4 \\
12.0 \\
19.8 \\
11.8\end{array}$ \\
\hline
\end{tabular}

transition point; 19 showed high readings at 20 minutes; 11 showed elevated final rod thresholds. Of 6 cases with almost normal readings, 4 had received vitamin A concentrates for from 3 to 12 months prior to testing. There was no apparent correlation between the severity of liver disease and the degree of derangement in dark adaptation.

\section{Response to therapy}

After preliminary tests were made, the patients with cirrhosis of the liver were fed a diet rich in meat, green vegetables, milk, fruit, and eggs. By calculation from food tables (24) it was estimated to provide at least 13,000 I.U. Vitamin A daily. It also contained supplements of Vitamin "B complex" and ascorbic acid, in the form of thiamin chloride, brewer's yeast, liver extract, and orange juice. On this regimen 2 patients showed moderate improvement in speed of adaptation after 7 months. However in 5 other cases, similarly treated, no changes occurred after intervals varying between 6 and 18 months.

Concentrates of vitamin $\mathrm{A}^{2}$ were then administered to several patients orally and parenterally in addition to the above diet. Detailed observations illustrating dosages used and the response to such therapy in 4 patients are shown in Figure 2. The upper curves, from Cases $C$ and $D$, reveal delayed cone-rod transition points and high rod and cone thresholds. Both of these functions improved strikingly after therapy. The lower curves, from Cases A and B, reveal marked delay at the transition point but no elevation in final thresholds of either rods or cones. These curves likewise reveal the return towards normal values after therapy. It is noteworthy that changes of rod function are confined almost entirely to alterations in speed.

Examination of the curves of Case D (Figure 2) reveals marked increases in the slope or speed of the cone function which parallel increments in the speed of the rod function. This subject had a pupil which was fixed with respect to light stimuli at a diameter of about $6 \mathrm{~mm}$.; whereas the other subjects, who showed no measurable change in cone speed, had normal pupillary light reflexes. Comparable improvements in the speed of the cone functions of Cases $\mathrm{A}, \mathrm{B}$, and $\mathrm{C}$ might have been detectable if a constant pupillary aperture had been employed in making the measurements. Just such a discrepancy between measurements made with and without a constant pupillary aperture are predictable from recent experiments (19) on the effect of the pupillary light reflex upon cone dark adaptation measurements.

In order to show the changes that occurred over several month' observations, the 20-minute rod readings were selected for comparison in these cases ( $c f$. Figures 3, 4, 5, 6). In Cases A

${ }^{2}$ A concentrate of the National Oil Products Co., Newark, N. J., was diluted with peanut oil to make appropriate doses. Oil for parenteral use was autoclaved in air-tight bottles. 

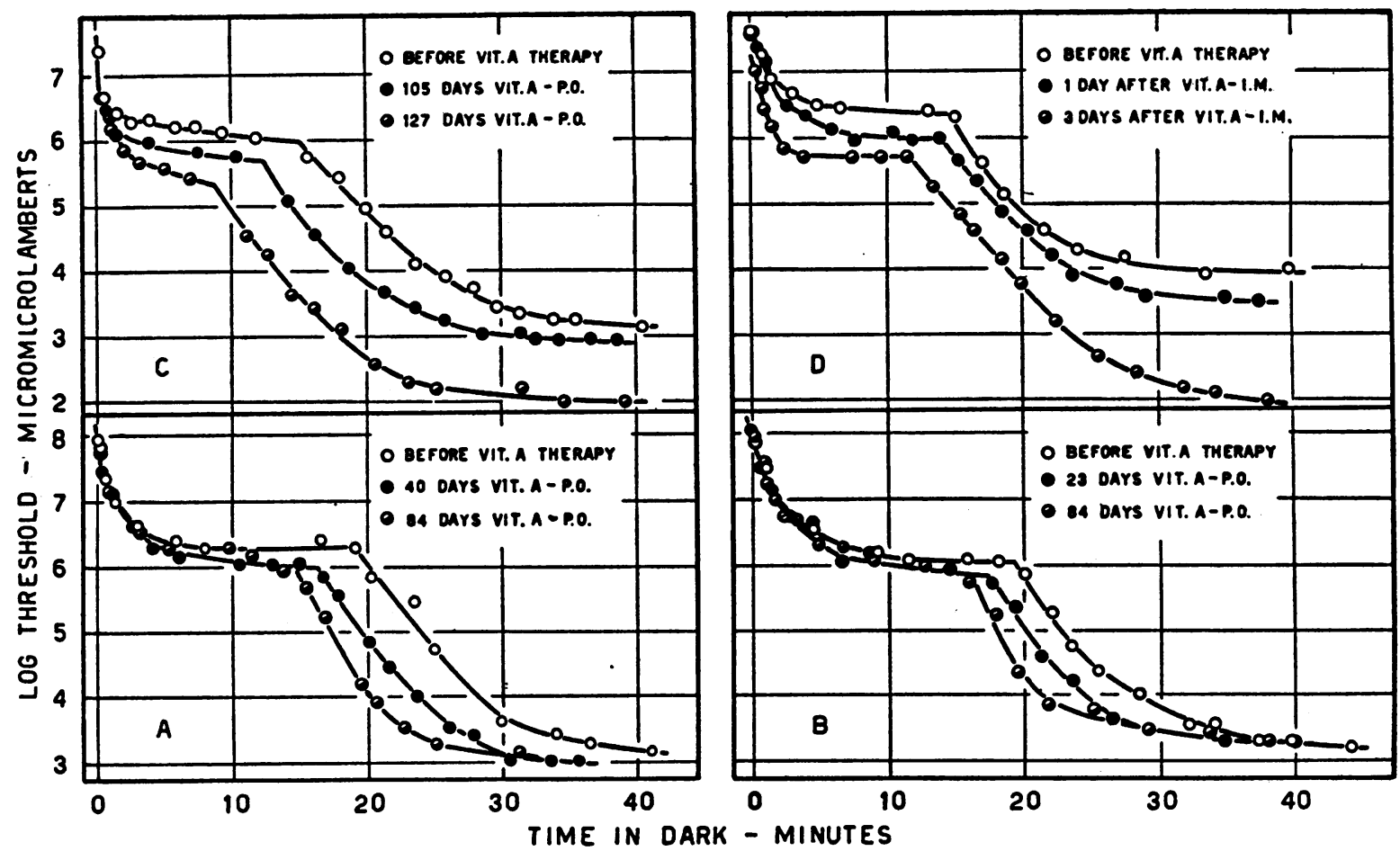

Fig. 2. Changes in Dark Adaptation of 4 Patients with Cirrhosis of the Liver during Vitamin A Therapy

The three curves drawn for each case are selected from actual readings made during the course of vitamin A therapy. The upper curves from Cases $C$ and D reveal high cone and rod final thresholds together with delay in rod adaptation. Following vitamin A therapy both of these functions improved. The procedure for measuring dark adaptation in Case $C$ was somewhat different from the standard technique employed in the other cases (14).

The lower curves from Cases A and B reveal normal final thresholds but abnormal delay at the cone-rod transition point. In patients with cirrhosis of the liver this type of change appears to be the more characteristic. These curves also show the improvement that follows vitamin A therapy.

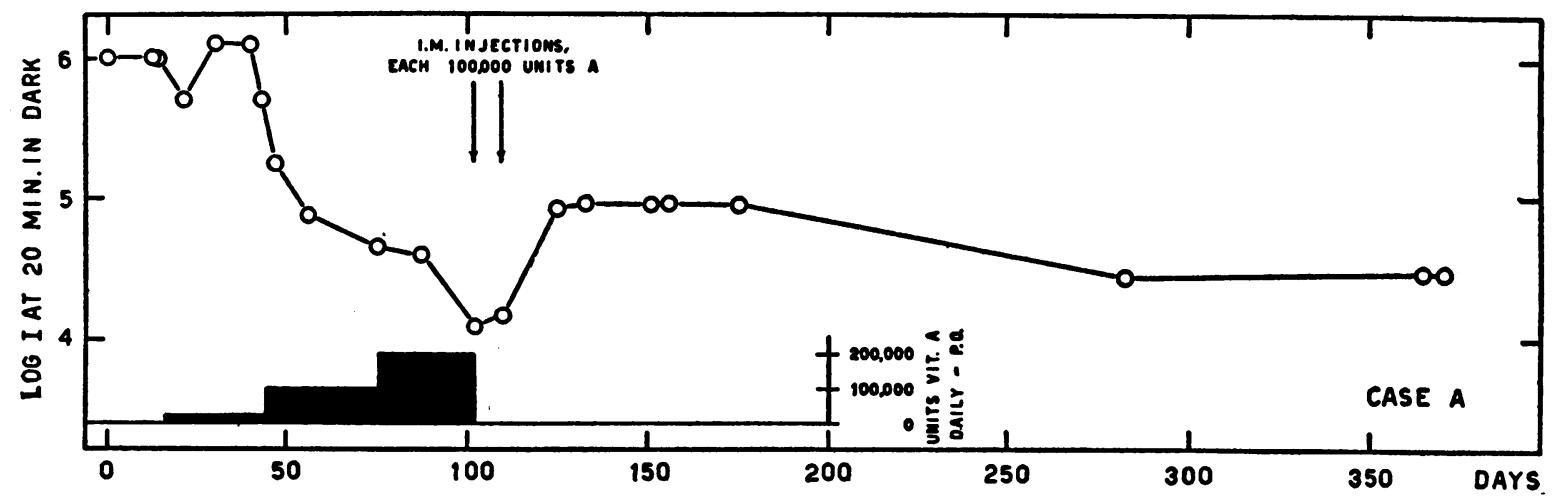

Fig. 3. Changes in the 20-Minute Dark adaptation Threshold with Vitamin A Therapy

The patient (Case A) was fed 10,000 I.U. vitamin A concentrate daily for 1 month without apparent benefit. This period was followed by 1 month with 100,000 I.U. daily, during which a significant improvement in dark adaptation was observed. The dose was then increased to 200,000 units daily, during which improvement continued. After 2 weeks of such therapy the patient received 2 injections intramuscularly of 100,000 units which caused no further change. On discontinuing treatment there followed a rise and subsequent decline of threshold. Partial improvement was maintained without specific therapy for 9 months. 


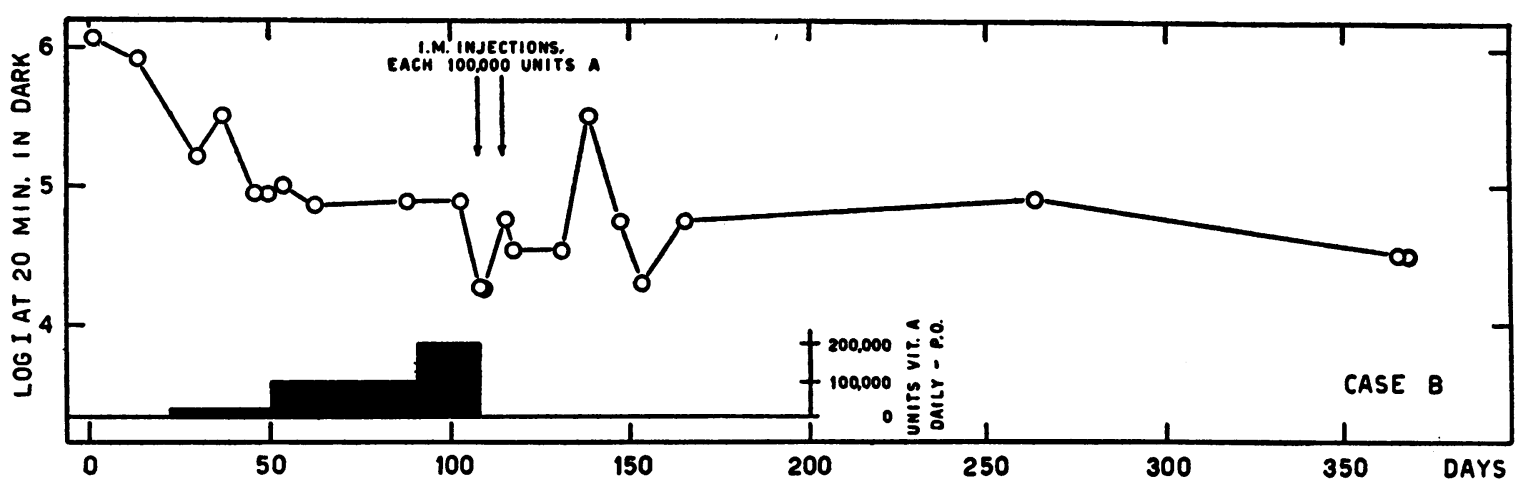

Fig. 4. Changes in the 20-Minute Dark Adaptation Threshold with Vitamin A Therapy

The patient (Case B) was treated similarly to Case A. In this patient, however, improvement was noted after feeding 10,000 I.U. vitamin A concentrate daily, which was not accelerated when the dose was increased to 100,000 units. A sharp decline in threshold followed the administration of 200,000 I.U. daily for 2 weeks. The intramuscular injection of 100,000 I.U. twice in the next 5 days caused no further change. On discontinuing therapy there followed an erratic rise and subsequent levelling of threshold. Partial improvement was maintained 9 months.

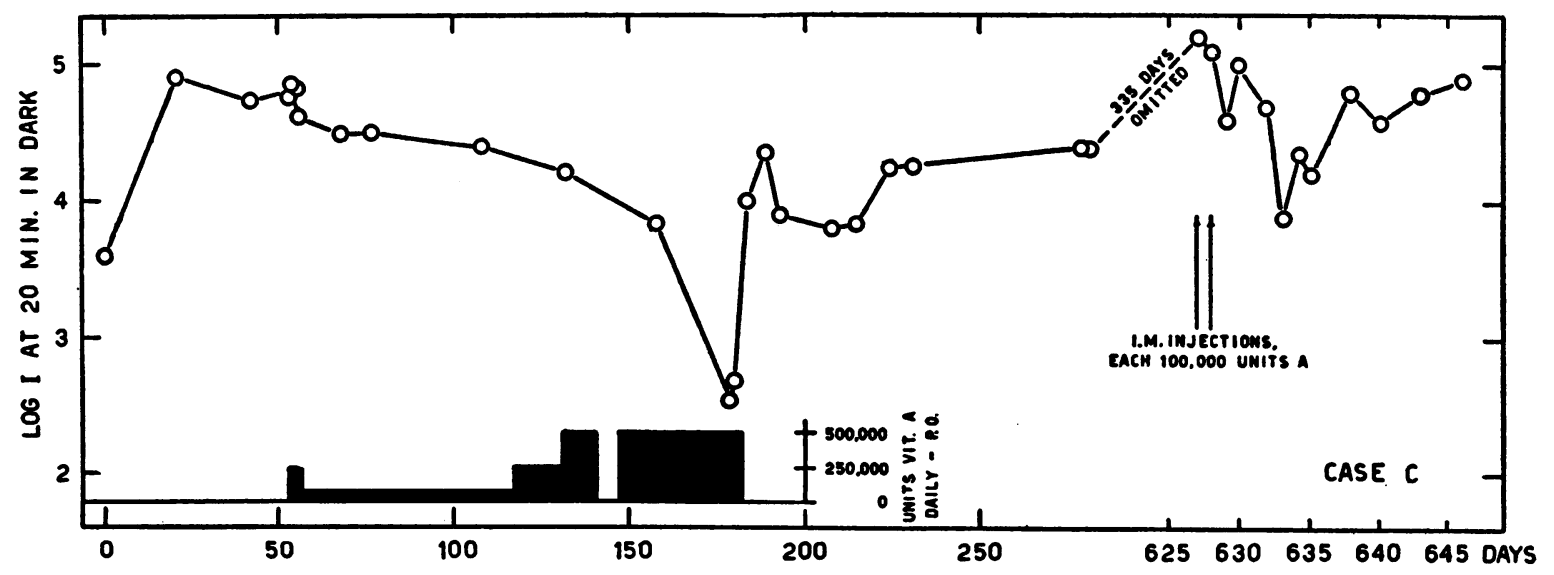

Fig. 5. Changes in the 20-Minute Dark Adaptation Threshold with Vitamin A Therapy

The course of Case $C$ was described in the preliminary report of this paper (14). The procedure for measuring dark adaptation in this instance was somewhat different from the technique employed in the other cases. The first point on the graph represents the 20-minute threshold value after he had received 40,000 units of vitamin A daily for 2 months. On discontinuing therapy the threshold rose abruptly. When treatment was resumed with 60,000 units daily, there followed a steady, slow improvement. Marked changes occurred only after the dose was increased to 500,000 units. A second rise in threshold followed the discontinuance of therapy. After 16 months had elapsed 2 intramuscular injections of 100,000 units each were administered. An abrupt fall in threshold took place, which again was poorly maintained.

and $\mathrm{B}$ the improvement in dark adaptation that followed oral feeding of vitamin A concentrate was partially maintained 9 months after specific therapy was discontinued. In Cases C and D, however, there was little tendency to maintain improvement without continual administration of vitamin $\mathrm{A}$. In both Cases $\mathrm{C}$ and $\mathrm{D}$ an abrupt but transitory benefit from intramuscular injec- bis

tions of vitamin A concentrate was observed. Because of the relatively large amounts of vitamin A that were necessary to bring about improvement in dark adaptation, and because of their slow response to therapy, these cases appear to be resistant to treatment. However, it should be stated that in sterilizing the oil preparation for parenteral use, the vitamin content probably was 


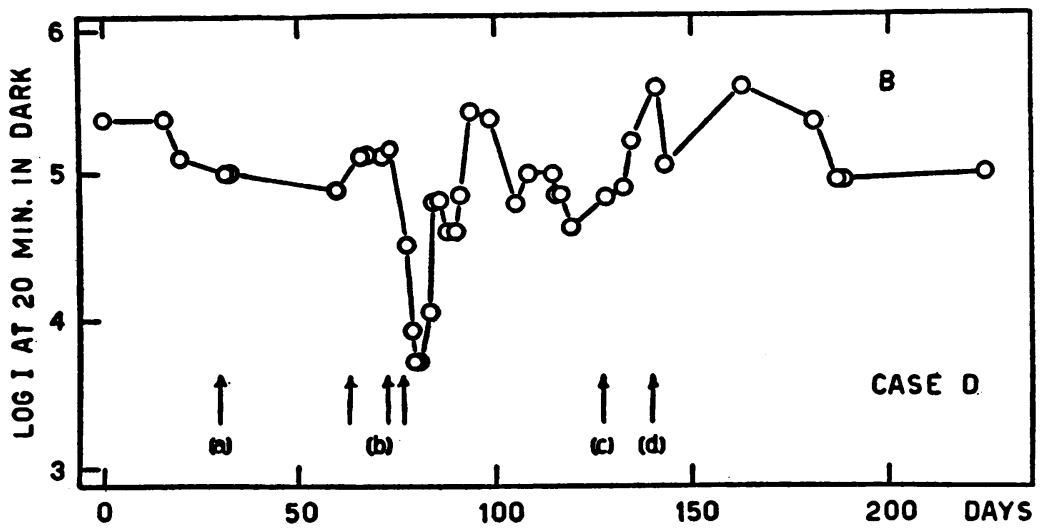

Fig. 6. Changes in 20-Minute Dark Adaptation with Parenteral VITAMIN A THERAPY

Vitamin A was administered by parenteral injection alone to this patient (Case D). After the injection (a) of 30,000 units vitamin A, little change occurred. Substantial improvement in dark adaptation took place only after he had received 3 intramuscular injections $(b)$ of 100,000 units each. The improvement lasted for 1 week. The intravenous injection of $1600(c)$ and $4400(d)$ units of colloidal carotene evoked no response.

reduced. Moreover, an inflammatory reaction at the site of injection may have impaired its availability.

In the course of observations it was apparent that subjective reactions or impressions of the patients were unreliable. None of them was aware of night blindness.

\section{DISCUSSION}

From the above data it is evident that patients with cirrhosis of the liver may be deficient in vitamin $A$. It is also evident that the deficient state is not attributable to inadequate intake of the vitamin in their food. Although the selected cases were free of jaundice, it is possible that malabsorption contributed to the deficiency. The patients' resistance to oral therapy might be so interpreted. However, if faulty absorption alone were the basis for the deficiency, it would be reasonable to expect a response like that seen in cases of simple deficiency or of obstructive jaundice (Figure 1, Curve 2), rather than the more complex derangement illustrated by Figure 1, Curve 3. In other words, patients with malabsorption of vitamin A should reveal elevations of cone and rod thresholds without alterations in the speed of rod adaptation. Moreover, parenteral injection of 300,000 I.U. should have provided more prompt and lasting effect, if lack of absorption from the intestine was the only cause of night blindness.

However, in view of discrepancies in recent reports on the response of normal subjects to a diet low in vitamin $A$ and to subsequent vitamin $A$ therapy, it would be premature to draw conclusions from the sluggish response of our patients to vitamin A therapy. Thus, Hecht and Mandelbaum (20) noted that the recovery period required weeks in normal subjects that had received a low vitamin $\mathrm{A}$ intake for $\mathbf{3 0}$ days. In a somewhat similar study Wald, Jeghers, and Arminio (21) observed a prompt return to normal values 80 minutes after oral therapy, and 20 minutes after parenteral therapy.

It may be argued that liver disease imposes a greater need for vitamin A because of increased catabolism. Whereas this may be so, a comparable change in dark adaptation was not observed in other conditions studied in which a general increase in metabolic needs takes place. Thus, 4 patients with lobar pneumonia who had experienced considerable fever and weight loss and 4 patients with active rheumatoid arthritis failed to show abnormal dark adaptation. 
There remains the implication that in addition to the above possible causes for vitamin A deficiency, the injured liver alters the intermediary metabolism of vitamin A. This is supported by the observation that certain cases show only delay of response but ultimately reach normal thresholds. In other words, the reserve for visual purple and hence vitamin $\mathrm{A}$ was sufficient to allow a normal threshold to be reached, but the regeneration of visual purple was impeded.

\section{SUMMARY AND CONCLUSIONS}

1. Abnormal dark adaptation was observed in 19 of 24 patients with cirrhosis of the liver.

2. In certain patients both elevation of the final rod and cone thresholds and delay of rod dark adaptation occurred. In most instances only the latter change took place.

3. These changes were unrelated to jaundice. They tended to persist in the presence of a nutritious diet, rich in vitamin $\mathrm{A}$.

4. The administration orally and parenterally of vitamin A concentrates was followed by extensive improvement. Cone and rod thresholds were lowered, and speed of adaptation was increased. After discontinuance of therapy this improvement was only partially maintained.

5. These findings suggest that abnormal dark adaptation in patients with cirrhosis of the liver is due chiefly to altered intermediary metabolism of vitamin $\mathrm{A}$.

\section{BIBLIOGRAPHY}

1. Wilbur, D. L., and Eusterman, G. B., Nutritional night blindness. Report of a case. J. A. M. A., 1934, 102, 364.

2. Jeghers, $H$., Night blindness as a criterion of vitamin A deficiency. Ann. Int. Med., 1937, 10, 1304.

3. Altschule, M. D., Vitamin A deficiency in spite of adequate diet in congenital atresia of bile ducts and jaundice. Arch. Path., 1935, $20,845$.

4. Lasch, F., Uber den Vitamin A-Spiegel im Blute bei Leberkrankheiten. Klin. Wchnschr., 1938, 17, 1107.

5. Breusch, F., and Scalabrino, R., Die quantitativen Verhältnisse der Leberlipoide. Ztschr. f. d. ges. exper. med., 1934, 94, 569.

6. Moore, T., The vitamin A reserve of the adult human being in health and disease. Biochem. J., 1937, 31, 155.
7. Kumagai, N., Zur Kenntnis der Bewegungsvorgänge in der Netzhaut. Mitt. a.d. Med. Fakult. d. k. Univ. zu Tokyo, 1916, 16, 137.

8. Ralli, E. P., Pariente, A., Flaum, G., and Waterhouse, A., A study of vitamin A deficiency in normal and depancreatized dogs. Am. J. Physiol., 1933, 103, 458.

9. Lasch, F., Vitamin A-Stoff wechsel und Leber Bei Experimenteller Phosphorvergiftung. Klin. Wchnschr., 1935, Nr. 30, 1070.

10. Greaves, J. D., and Schmidt, C. L., The utilization of carotene by jaundiced and phosphorous treated vitamin A deficient rats. Am. J. Physiol., 1935, 111, 502.

11. Althof, H., and Müller, H., Störungen des Sehvermögens neben solchen der Leberthatigkeit. Würzb. Med. Ztschr., 1861, 2, 349.

12. Dolganoff, W., Ueber die Veränderungen des Auges nach Ligatur der Gallenblase. Arch. f. Augenh., 1897, 34, 196.

13. Greaves, J. D., and Schmidt, C. L., On the absorption and utilization of carotene and vitamin $A$ in choledochocolonostomized vitamin A deficient rats. Am. J. Physiol., 1935, 111, 492.

14. Haig, C., Hecht, S., and Patek, A. J., Jr., Vitamin A and rod-cone dark adaptation in cirrhosis of the liver. Science, 1938, 87, 534.

15. Fridericia, L. S., and Holm, E., Experimental contribution to the study of the relation between night blindness and malnutrition. Am. J. Physiol., 1925, $73,63$.

16. Tansley, $K$., The regeneration of visual purple: its relation to dark adaptation and night blindness. $\mathrm{J}$. Physiol., 1931, 71, 442.

17. Wald, G., Carotenoids and the visual cycle. J. Gen. Physiol., 1935, 19, 351.

18. Hecht, S., and Shlaer, S., An adaptometer for measuring human dark adaptation. J. Optic Soc. America, 1938, 28, 269.

19. Haig, C., The influence of the pupillary light reflex upon dark adaptation measurements. Anat. Rec., 1938, 72, suppl., 82.

20. Hecht, S., and Mandelbaum, J., Rod-cone dark adaptation and vitamin A. Science, 1938, 88, 219.

21. Wald, G., Jeghers, H., and Arminio, J., An experiment in human dietary night blindness. Am. J. Physiol., 1938, 123, 732.

22. Booher, L. E., Callison, E. C., and Hewston, E. M., An experimental determination of the minimum vitamin $\mathrm{A}$ requirements of normal adults. J. Nutrition, 1939, 17, 317.

23. Ezickson, W. J., and Feldman, J. B., Signs of vitamin A deficiency in the eye correlated with urinary lithiasis. J. A. M. A., 1937, 109, 1706.

24. Daniel, E. P., and Munsell, H. E., Vitamin Content of Foods. U. S. Dept. Agric. misc. publ. 275, June 1937. 